\title{
Comparison of the effects of insulin, PDGF, interleukin-6, and interferon- $\gamma$ on glucose transport in 3T3-L1 cells: lack of cross-talk between tyrosine kinase receptors and JAK/STAT pathways
}

\author{
C. H uppertz ${ }^{1}$, C. Schwartz ${ }^{2}$, W. B ecker ${ }^{1}$, F. H orn'ㄹ, P. C. H einrich², H .-G . J oost ${ }^{1}$ \\ ${ }^{1}$ Institut für Pharmakologie und Toxikologie der RWTH A achen, Germany \\ ${ }^{2}$ Institut für B iochemie der RWTH A achen, Germany
}

Summary The effects of insulin, insulin-like growth factor (IGF)-I, platelet-derived growth factor (PD G F), interleukin (IL )-6 and interferon- $\gamma$ on 2-deoxyglucose uptake and insulin receptor substrate (IR S)-1 phosphorylation were compared in 3T 3-L 1 cells at confluence and after differentiation to the adipocyte-like phenotype. Insulin and IG F-I produced the expected stimulation of glucose transport and tyrosine phosphorylation of IRS-1 in both confluent and differentiated cells. In contrast, IL -6 and interferon- $\gamma$ failed to stimulate glucose transport or IR S1 phosphorylation, although a marked stimulation of the JA K/STA T pathways as shown by acute-phase response factor (A PR F)/Stat3 or Stat1 activation was observed in fibroblasts (IL -6 , interferon- $\gamma$ ) and adipocytes (IL -6). PD G F-A A and PDG F-B B stimulated glucose transport in confluent, undifferentiated cells to the same extent as insulin (approximately six-fold stimulation), but produced only a small portion of the effect of insulin in differentiated cells. Similarly,
mR NA levels and autophosphorylation of PD G F receptors were much lower in differentiated cells than in confluent fibroblasts. In contrast to insulin and IG F-I, PD G F failed to stimulate tyrosine phosphoryIation of IRS-1. A II effects of insulin, IGF-I, and PDGF on glucose transport were inhibited by Wortmannin; the half-maximally inhibiting concentration $\left(\mathrm{IC}_{50}\right)$ of Wortmannin was increased by insulin. These data demonstrate distinct signalling potentials of the investigated receptors, and indicate that the I L -6 and interferon- $\gamma$ controlled JAK/STA T pathways lack the potential to stimulate glucose transport. IRS-1 does not appear to be involved in the PD G F receptor-mediated effects, whereas activation of phosphatidylinositol (PI) 3-kinase is a crucial event in all pathways leading to stimulation of glucose transport. [D iabetologia (1996) 39: 1432-1439]

Keywords Insulin, glucose transport, tyrosine kinase, 3T 3-L 1 cells, PD G F receptor.
R eceived: 14 D ecember 1995 and in final revised form: $26 \mathrm{~A} \mathrm{u-}$ gust 1996

Corresponding author: Dr. H.G. Joost, Institut für Pharmakologie und Toxikologie, M edizinische Fakultät der RWTH A achen, Wendlingweg 2, D -52057 A achen, G ermany

A bbreviations: PDG F, Platelet derived growth factor; PDG F $\mathrm{R}$, platelet derived growth factor receptor; IG F-I, insulin-like growth factor I; IR, insulin receptor; IRS-1, insulin receptor substrate $1 ;$ JA K, Janus kinase; STAT, signal transducer and activator of transcription; GLUT1, erythrocyte-type glucose transporter 1; GLUT4, adipose/muscle-type glucose transporter; IL -6, interleukin 6; sI L-6R, soluble receptor of interleukin 6; IL-4, interleukin 4; KR H, K rebs- $\mathrm{R}$ inger $\mathrm{H}$ epes buffer; BSA, bovine serum albumin; E GF, epidermal growth factor; A PR F, acute-phase response factor.
Several growth factors exert their mitogenic effect through the intrinsic tyrosine kinase activity located at the intracellular domain of their receptors [1]. The common event in the signal transduction of these receptors is the formation of a multimeric complex comprising the phosphotyrosine domains of the receptor and $\mathrm{SH} 2 / \mathrm{SH} 3$ domains of effector or adapter proteins [2-4]. The phosphorylated platelet derived growth factor (PDGF) receptor appears to directly interact with $\mathrm{SH} 2$ domains in phosphatidylinositol (PI) 3-kinase or other proteins [5,6]. Similarly, phosphorylated epidermal growth factor (E G F)-receptors have been shown to form a complex including the SH 2/SH 3 adapter G rb-2 and the GTP exchange factor Sos-1 which subsequently activates Ras [7]. In 
contrast, insulin receptors phosphorylate substrates (IR S-1 and IR S-2) on tyrosine residues that appear to constitute the docking sites for $\mathrm{SH} 2$ domains in other proteins, e.g. PI 3-kinase [8, 9].

In mammals, there is a clear functional distinction between insulin receptors and other members of the protein tyrosine kinase family. Whereas insulin receptors regulate metabolic pathways, e.g. the transport of glucose in muscle and adipose tissue, all other tyrosine kinase receptors so far identified appear to control cell growth. Consequently, the question arises whether this specificity reflects a heterogeneity of the signalling pathways, or whether it is the expression and the selectivity of the receptors alone that determine the cellular responses. If the second possibility was true, one would expect that other tyrosine kinase receptors could mimick the metabolic effects of insulin in cells equipped with an insulin-sensitive glucose transport and the respective growth factor receptor.

We have previously employed 3T 3-L 1 preadipocytes in order to address this question [10]. This cell acquires a moderate insulin sensitivity of glucose transport at confluence, and a marked insulin sensitivity after differentiation to an insulin-like phenotype [11-14]. A comparison of the effects of insulin and IGF-I on glucose transport in the differentiated cells indicated that the I G F-I receptor, the closest relative of the insulin receptor, is capable of stimulating the same response of glucose transport as the insulin receptor [10]. In contrast, more recent work by others has suggested that the PDG F receptor lacks the potential to exert an insulin-like effect on glucose transport in 3T 3-L 1 adipocytes [15-17].

R ecently, it was shown that IR S-1, the main substrate of the insulin receptor kinase, is phosphorylated in response to I L -4 , suggesting that the pathways controlled by cytokines may interact with those controlled by insulin and growth factors $[18,19]$. In the present study we investigated the effects of interleukin 6 (IL-6), interferon- $\gamma$, and IL -4 on glucose transport. IL -6 was chosen because it can stimulate cells lacking I $\mathrm{L}-6$ receptors through an exogenously added soluble receptor protein which binds to the ubiquitously expressed signal transducer of the IL -6 receptor, gp130 [20, 21]. I L - 6 and interferon- $\gamma$ activate the transcription factors acute-phase response factor (A PR F )/Stat3 or Stat1, respectively, through the tyrosine kinases Jak1, Jak2 and Tyk2 [22, 23], whereas I L -4 activates Stat6 through Jak 1 and Jak3 [23]. O ur data indicate that IL -6 and interferon- $\gamma$ receptors lack the potential to stimulate glucose transport in both phenotypes of the 3T 3-L 1 cells. PD G F receptors, in contrast, produce a full insulin-like effect in confluent 3T 3-L 1 fibroblasts which differs from that produced by insulin by the absence of any detectable IRS-1 phosphorylation. In addition, we show that the incomplete stimulation of glucose transport by
PDGF in the differentiated cells is paralleled by a markedly reduced expression of PD G F-receptors.

\section{Materials and methods}

Cell culture. 3T 3-L 1 fibroblasts were obtained from the A merican Type Culture Collection (R ockville, M d., U SA ) and were grown and differentiated as described previously [10].

A ssay of glucose transport. C onfluent 3T 3-L 1 fibroblasts (day 7 after plating) or differentiated cells (day 9 after induction of differentiation) were washed with K rebs- $\mathrm{R}$ inger $\mathrm{H}$ epes buffer ( $\mathrm{KRH}$ ) supplemented with $0.2 \%$ bovine serum albumin (BSA ), and were incubated for $2 \mathrm{~h}$ in serum free culture medium containing $1 \%$ BSA. Thereafter, cells were washed two times with $\mathrm{KRH}$ containing $0.2 \% \mathrm{BSA}$ and were incubated for $20 \mathrm{~min}$ in this buffer supplemented with $1 \%$ BSA (basal) and the indicated concentrations of hormones. R ecombinant IGF-I was a gift from Ciba-Geigy (B asel, Switzerland); PDGF-AA, PDGF-BB, and IL-4 were purchased from $B a-$ chem (B ubendorf, Switzerland). I L - 6 and the soluble IL -6 receptor were prepared as described previously [24]. R ecombinant rat interferon- $\gamma$ was a gift from D r. M.L. L ohmann-M atthes, A bteilung Immunologie, Fraunhofer Institut, $\mathrm{H}$ annover. G lucose transport activity was determined with $2-\left[{ }^{3} \mathrm{H}\right]$ deoxyglucose as described previously [10].

P reparation of nuclear extracts and gel retardation assay. 3T 3$\mathrm{L} 1$ fibroblasts and adipocytes were kept for $2 \mathrm{~h}$ in serum-free culture medium ( $1 \%$ BSA ), and were stimulated for $15 \mathrm{~min}$ as indicated with I L $-6 / 5 \mid \mathrm{L}-6 \mathrm{R}$, interferon- $\gamma$ or with insulin. N uclear extracts were prepared as described [25]. G el retardation assays were performed according to a modification of a published procedure [26]. A ${ }^{32} \mathrm{P}$-labelled synthetic oligonucleotide (5'-G A TCTA G CA TTTCCCGTA A A TCCCTCCCG -3') corresponding to SIE m67 (sis-inducible element of the c-fos promoter) was used as a probe. Nuclear extracts ( $5 \mu \mathrm{g}$ of protein) were incubated with about $10 \mathrm{fmol}(5,000 \mathrm{cpm})$ of probe in gel shift incubation buffer [10 mmol// $\mathrm{H}$ epes, $\mathrm{pH} 7.8,1 \mathrm{mmol} / \mathrm{l}$ EDTA , $5 \mathrm{mmol} / \mathrm{l}$ magnesium chloride, $10 \%$ (v/v) glycerol, $1 \mathrm{mmol} / \mathrm{l}$ dithiothreitol, $0.07 \mathrm{mmol} / /$ phenylmethylsulfonyl fluoride, $0.1 \%$ BSA , $0.05 \mathrm{mg} / \mathrm{ml}$ poly (dldC) (Pharmacia, Freiburg, Germany)] for $10 \mathrm{~min}$ at room temperature. The D NA protein complexes formed were then separated by native gel electrophoresis on a $5 \%$ polyacrylamide gel containing $7.5 \%$ glycerol, $22 \mathrm{mmol} / \mathrm{l}$ Tris borate and $0.5 \mathrm{mmol} / \mathrm{l}$ E DTA, pH 8.3.

Preparation of cell lysates and immunoprecipitation. U ndifferentiated or differentiated 3T 3-L 1 cells were stimulated with the indicated agents, and were lysed for $5 \mathrm{~min}$ in a boiling SD S-buffer $(20 \mathrm{mmol} / \mathrm{l}$ Tris, pH 7.4, 1\% SD S). The lysates were then sonicated briefly for $15 \mathrm{~s}$. A pproximately $250 \mu \mathrm{l}$ of the lysates ( $1 \mathrm{mg}$ of total protein) were incubated for $2 \mathrm{~h}$ with $5 \mu \mathrm{g}$ of phosphotyrosine antibody (PY 20, Transduction L aboratories, Lexington, $\mathrm{Ky}$., USA) in a buffer containing $20 \mathrm{mmol} / \mathrm{l}$ Tris, $\mathrm{pH} 7.4,150 \mathrm{mmol} / \mathrm{l}$ sodium chloride, $0.2 \mathrm{mmol} /$ I phenylmethylsulfonyl fluoride and $1 \%$ Triton $X-100\left(4{ }^{\circ} \mathrm{C}\right)$. Immunocomplexes were adsorbed to protein A sepharose (Pharmacia), washed three times with buffer containing $20 \mathrm{mmol} / \mathrm{l}$ Tris $\mathrm{pH} 7.4,150 \mathrm{mmol} / \mathrm{l}$ sodium chloride and $0.1 \%$ Triton $X-100$, two times with the same buffer containing $0.05 \%$ Triton $X-100$ and eluted with electrophoresis sample buffer. The samples were separated by SD S-PA G E and transferred onto nitrocellulose membrane (Schleicher and Schuell, Dassel, Germany) with a tank-blot apparatus (Pharmacia). 
M embranes were incubated for $2 \mathrm{~h}$ at room temperature with the phosphotyrosine antibody PY 20 at a dilution of 1:1000 or with the antiserum against IR S- 1 (anti-R at carboxy-terminal IR S-1, U BI, Lake Placid, N.Y., USA ) at a dilution of 1:200. Bound immunoglobulin was detected with ${ }^{125}$-protein $A$ (A mersham-Buchler, Braunschweig, G ermany).

Preparation of RNA and synthesis of $C D N A$. Total R NA was prepared by centrifugation on cesium chloride as described previously [10]. First-strand CD NA was synthesized from adipocyte RNA with murine reverse transcriptase (First-strand CD N A synthesis-kit, Pharmacia) by oligo-dT priming.

Northern blot analysis. D enatured samples of total RNA $(20 \mu \mathrm{g})$ were separated by electrophoresis on $1 \%$ agarose gels and transferred on to nylon membranes ( $\mathrm{H}$ ybond $\mathrm{N}^{+}$; $A$ mersham-Buchler). B efore transfer, gels were stained with ethidium bromide in order to ascertain that equal amounts of total RNA had been separated. CDNA probes corresponding with the subdomains VI to IX of the catalytic domain of PD G F receptors were generated by PCR (PDG F $\alpha$-receptor, bp 26352837, G enBank accession no. M 84607; PD GF $\beta$-receptor, bp 2620-2847, accession no. X 04 367) with CD N A from differentiated cells. The probes were labelled by random oligonucleotide priming with the K lenow fragment of DNA polymerase $I$ and $\left.{ }^{32} \mathrm{P}\right]$ CTP. The nylon membranes were hybridized at $42^{\circ} \mathrm{C}$, and blots were washed three times with $0.12 \mathrm{~mol} / \mathrm{l}$ $\mathrm{NaCl} / 0.012 \mathrm{~mol} / /$ sodium citrate $/ 0.1 \% \mathrm{SD} \mathrm{S}$ at $55^{\circ} \mathrm{C}$.

\section{Results}

Comparison of the effects of insulin, IL -6 and interferon- $\gamma$ on glucose transport in 3T 3-L 1 cells. The cytokine IL -6 stimulates activation of the transcription factor APR F/Stat3 in a number of cells via a JA K/ STA T pathway $[22,27]$. In order to compare this signalling pathway with that of tyrosine kinase receptors, we characterized the effects of insulin and IL-6 on APR F/Stat3-activation and glucose transport in 3T 3-L 1 cells. 3T 3-L 1 fibroblasts and adipocytes were treated with insulin or with human IL-6. Since we supposed that 3T 3-L 1 cells have only a low number of I $L-6$ receptors, the soluble I L - 6 receptor ( $s I L-6 R$ ) was added together with IL- 6 in separate samples. Proteins were extracted from the nuclei and analysed in gel retardation assays. A s is illustrated in Figure 1 (upper panel), a retarded band appeared in extracts from 3T 3-L 1 fibroblasts treated with IL -6 . This band represents a complex of the DNA probe with the activated homodimer of APR F and its hetero-dimer of A PR F and Stat1; their mobilities were identical with those of the complexes formed by the A PR F heteroand homodimers in H epG 2 cells stimulated with IL 6 (control). F urthermore, the addition of soluble IL 6 receptor to the medium markedly enhanced the effect of I L -6 . This finding indicates that I $L-6$ receptors are limiting for the A PR F activation in 3T 3-L 1 cells. In contrast to IL -6 , insulin failed to stimulate A PR F activation in both fibroblasts and adipocytes.

The lower panel of Figure 1 illustrates the effects of I L - 6 and insulin on glucose transport (2-deoxyglucose
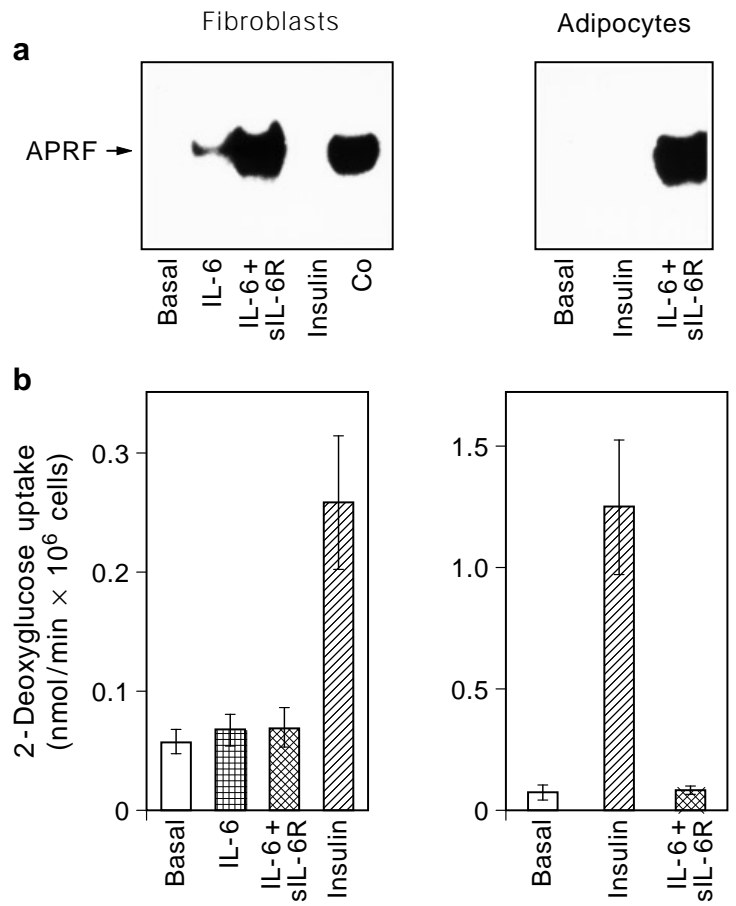

Fig. 1 a, b. E ffects of insulin and IL -6 on A PR F/Stat3 activation and glucose transport in 3T 3-L 1 cells. a) A ctivation of A PR F in 3T 3-L 1 fibroblasts and adipocytes by IL -6 in the presence or absence of soluble IL - 6 receptor ( $s$ I L-6R), and lack of effect of insulin. 3T 3-L 1 cells were treated for 15 min with human IL-6 (200 units/ml) and sl L-6R $(400 \mathrm{ng} / \mathrm{ml})$ or insulin $(250 \mathrm{nmol} / \mathrm{l})$. Nuclear extracts were prepared and subjected to a gel retardation assay as described, using $5 \mu \mathrm{g}$ of nuclear protein per lane and a ${ }^{32} \mathrm{P}$-labelled SIE m67 (sis-inducible element of the c-fos promoter) probe. A sa control (Co) $5 \mu \mathrm{g}$ of nuclear extract from $\mathrm{H}$ epG 2 cells treated with IL -6 were used. b) Effect of insulin on glucose uptake in 3T 3-L 1 fibroblasts and 3T 3-L 1 adipocytes, and lack of effect of IL -6/sl L 6-R . 3T 3-L 1 cells were treated for 20 min without or with human I L -6 (200 $\mathrm{U} / \mathrm{ml})$, IL -6 and $\mathrm{sl} \mathrm{L}-6 \mathrm{R}(400 \mathrm{ng} / \mathrm{ml})$ or insulin $(250 \mathrm{nmol} / \mathrm{l})$. G lucose uptake was determined with tritiated 2-deoxyglucose as described in $M$ aterials and methods. $D$ ata represent means \pm SEM of three independent experiments, each performed with duplicate samples

uptake). Insulin exerted a moderate (four-fold) stimulation of the 2-deoxyglucose uptake in confluent fibroblasts. A s was previously shown [14, 13], this effect is due to the translocation of G LUT 1 from an intracellular pool which is formed during growth of cells to confluence but prior to the initiation of differentiation. In differentiated cells, the anticipated large increase of glucose transport activity was observed (16-fold, note also the different scales of the ordinate). I n contrast, glucose transport was unresponsive to IL -6 or the combination of IL -6 with its soluble receptor.

The cytokine interferon- $\gamma$ stimulates J ak 1 and Jak2 through its receptor independent of the gp130 subunit of the IL -6 receptor. This effect of interferon- $\gamma$ was shown in 3T 3-L 1 cells by a marked activation of Stat1 and a weak activation of APRF/Stat3 as 
a
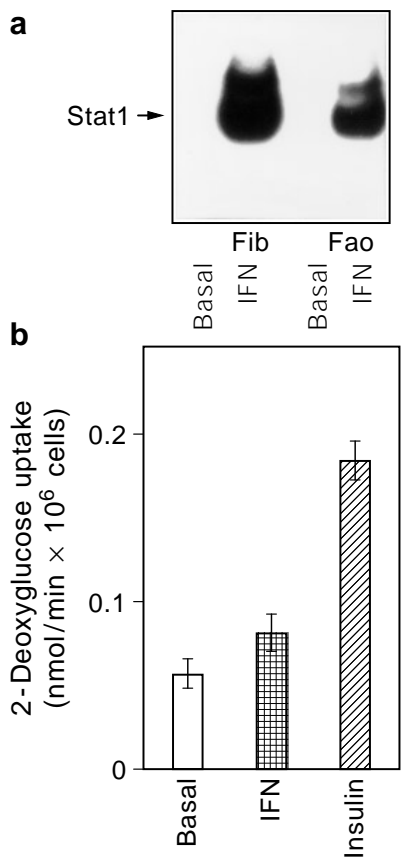

Fig. 2. E ffects of interferon- $\gamma$ (IFN) and insulin on Statl activation and glucose transport in 3T 3-L 1 cells. a) C onfluent 3T 3-L 1 cells (Fib) or Fao cells (Fao) were treated for 15 min with rat interferon- $\gamma$ ( 500 and 250 units/ml, respectively), and nuclear extracts were prepared and subjected to a gel retardation assay as described. b) Confluent 3T3-L 1 cells were treated for $20 \mathrm{~min}$ with or without rat interferon- $\gamma(500 \mathrm{U} / \mathrm{ml})$ or insulin $(250 \mathrm{nmol} / \mathrm{l})$. G lucose uptake was determined with tritiated 2deoxyglucose as described in $M$ aterials and methods. $D$ ata represent means \pm SE $M$ of three independent experiments

demonstrated in the gel retardation assay (upper panel of Fig. 2). In contrast, interferon- $\gamma$ failed to produce an insulin-like stimulation of glucose transport in confluent fibroblasts (Fig. 2, lower panel) or adipocytes (data given in next paragraph).

IL -6 and interferon- $\gamma$ are believed to produce STA T activation through the tyrosine kinases Jak1 and Jak2 and Tyk2, whereas other interleukins, e.g. IL -4, appear to require Jak3 [23]. Thus, experiments with IL -4 were performed. L ike IL -6 and interferon$\gamma$, IL -4 failed to stimulate an insulin-like response of glucose transport in both fibroblasts and adipocytes (Confluent fibroblasts: basal uptake rate, $0.042 \pm$ 0.005 ; I L - 4, $0.058 \pm 0.009$; insulin, $0.189 \pm 0.015$. A dipocytes: basal uptake rate, $0.064 \pm 0.005$; IL -4 , $0.083 \pm 0.002$; interferon- $\gamma, 0.089 \pm 0.004$; insulin, $0.713 \pm 0.018 \mathrm{nmol} /\left(\mathrm{min} \times 10^{6}\right.$ cells $)$.

Comparison of the effects of insulin, I G F - I, I L -6, IL 4 , and interferon- $\gamma$ on IR S-1 phosphorylation in 3T 3$L 1$ cells. In order to compare the effects of insulin, IG F-I I IL-6, IL -4 and interferon- $\gamma$ on tyrosine phosphorylation of the insulin receptor substrate IR S-1, 3T 3-L 1 cells were treated with the agents, lysed, and the lysates were incubated with the monoclonal antibody (PY 20) against phosphotyrosine. The immunoprecipitates were analysed by Western blotting with the same antibody. A s is illustrated in Figure 3a, insulin and IGF-I stimulated the tyrosine phosphorylation of a $160 \mathrm{kD}$ a protein in both fibroblasts and adipocytes. In parallel immunoblots with a specific antiserum (data not shown), this band was identified as IR S-1. In the fibroblasts, the magnitude of the phosphorylation in response to insulin was identical to that elicited by IG F-I. In the adipocytes, insulin produced an approximately five-fold higher tyrosine phosphorylation of IR S-1 than IG F-I (quantitation by laser densitometry: basal, $0.052 \pm 0.026$ arbitrary units; insulin, $3.03 \pm 0.23$; IG F-I $0.71 \pm 0.14$; means \pm SE M of three experiments). The weaker effect of IGF-I appears to correspond with the lower number of IGF-I receptors in differentiated 3T3-L 1 cells [10]. Glucose transport stimulation by insulin and IG F-I was assayed in parallel experiments. A s anticipated [10], both hormones produced an essentially identical stimulation of 2-deoxyglucose uptake (basal fibroblasts, $0.046 \pm 0.01$; insulin, $0.213 \pm 0.05$; IG F-I, $0.243 \pm 0.03$; basal adipocytes, $0.068 \pm 0.001$; insulin $1.36 \pm 0.18$; I G F-I , $1.25 \pm 0.07 \mathrm{nmol} /\left(\mathrm{min} \times 10^{6} \mathrm{cells}\right)$, means \pm SE M of three experiments). Thus, a submaximal IRS-1 phosphorylation as seen with IGF-I appears to be sufficient to elicit a full stimulation of glucose transport.

In contrast to the effects of insulin and IGF-I on IR S-1 phosphorylation, IL-6/SIL-6R, interferon- $\gamma$ and IL-4 failed to stimulate any detectable IR S-1 phosphorylation in 3T 3-L 1 adipocytes (Fig. 3b). It should be noted that the cytokines produced a very weak phosphorylation of an unidentified band which migrates with a slightly higher electrophoretic mobility $(155 \mathrm{kDa})$ than IRS-1 (160 kD a). In addition, phosphorylation of two other unidentified bands (116 and $135 \mathrm{kDa}$ ) was detected in adipocytes, but was not altered by any of the hormones or cytokines.

D ifferential expression of PD G F-receptors in 3T 3-L 1 cells and effects of PDGF on glucose transport. It has previously been shown that PD G F stimulates glucose transport in differentiated 3T 3-L 1 cells to a much lower extent than insulin [15-17]. In contrast, PI 3-kinase appeared fully stimulated by PD G F in 3T 3-L 1 adipocytes $[16,17]$. In order to detect possible differences between fibroblasts and adipocytes in the abundance of receptorsand/or the signal transduction, we studied the effects of PD GF on the receptor autophosphorylation and on tyrosine phosphorylation of receptor substrates. A s is illustrated in Figure 3c, PD G F produced a strong tyrosine phosphorylation of a 190 $\mathrm{kD}$ a protein in 3T 3-L 1 fibroblasts, corresponding with the PD G F receptor. In contrast, autophosphorylation of the PDGF receptor in the adipocytes was only $20 \%$ (laser densitometry: fibroblasts, $0.98 \pm 0.16$ arbitrary units; adipocytes $0.20 \pm 0.06$; means \pm SE M ) of that seen in the fibroblasts. A $s$ anticipated, insulin markedly stimulated tyrosine phosphorylation of 


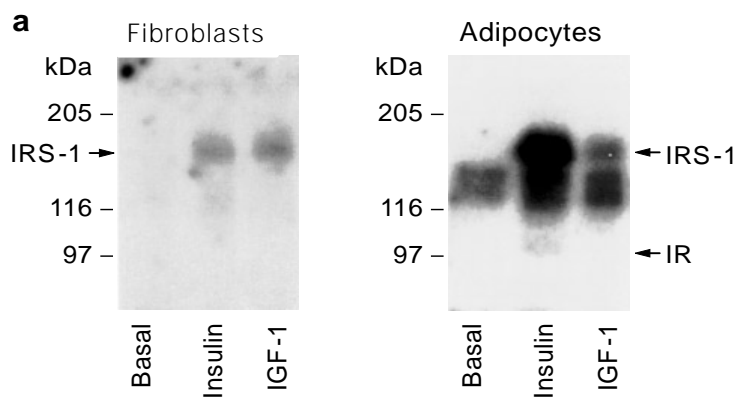

b

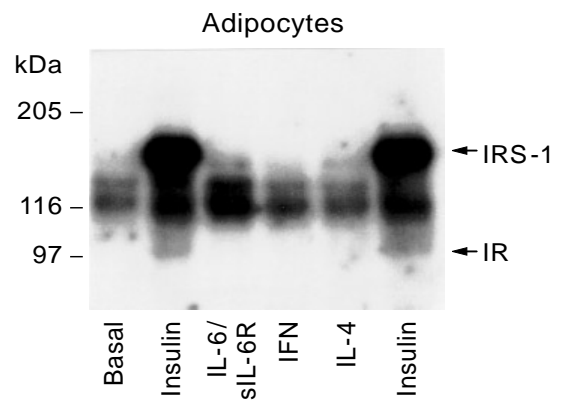

C

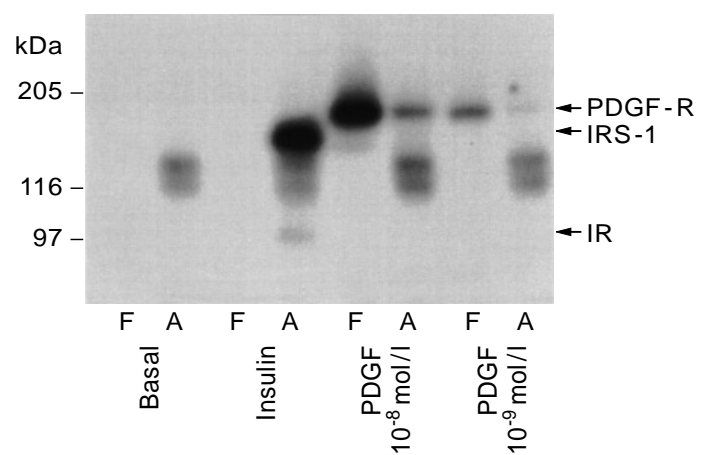

Fig. 3 a-c. Comparison of the effects of insulin, I G F-I, I L -6, interferon- $\gamma$, IL -4 and PD G F on IR S-1 phosphorylation in 3T 3$L 1$ cells. a) IR S-1 phosphorylation in 3T 3-L 1 fibroblasts and adipocytes in response to insulin and IGF-I. The cells were treated for $2 \mathrm{~min}$ without or with insulin ( $250 \mathrm{nmol} / \mathrm{l}$ ) or IG F-I $(10 \mathrm{nmol} / \mathrm{l})$ and lysed in SD S-buffer. Phosphoproteins in the lysates were immunoprecipitated with antibody against phosphotyrosine (PY 20). I mmunoprecipitates were separated by SD SPA GE , transferred on to nitrocellulose and probed with PY 20. In separate immunoblots with specific antiserum (not shown), the identity of I R S-1 was confirmed. b) L ack of effect of I L - 6 , interferon- $\gamma(I F N)$, and I L -4 on IR S-1 phosphorylation in 3T 3-L 1 adipocytes. D ifferentiated 3T 3- $L 1$ cells were treated for $15 \mathrm{~min}$ with insulin $(250 \mathrm{nmol} / \mathrm{l})$, I L - $6(200 \mathrm{U} / \mathrm{ml})$ plus sl L -6R $(400 \mathrm{ng} /$ $\mathrm{ml})$, interferon- $\gamma(500 \mathrm{U} / \mathrm{ml})$ or IL $-4(1000 \mathrm{U} / \mathrm{ml})$ and lysed in SD S-buffer. Phosphoproteins in the lysates were isolated and detected as described above. c E ffects of insulin and PD G F on IR S-1 phosphorylation in 3T 3-L 1 cells. U ndifferentiated ( $\mathrm{F}$, fibroblasts) and differentiated (A , adipocytes) 3T 3-L 1 cells were incubated for $2 \mathrm{~min}$ without or with insulin $(250 \mathrm{nmol} / \mathrm{l})$ or PDGF-BB $\left(10^{-8} \mathrm{~mol} / \mathrm{l}, 10^{-9} \mathrm{~mol} / \mathrm{l}\right)$ and lysed in SD S-buffer. Phosphoproteins in the lysates were isolated and detected as described above

IR S-1 ( 160 kD a) in the adipocytes. In contrast, PD G F failed to stimulate any detectable I R S-1 phosphorylation in either fibroblasts or adipocytes.

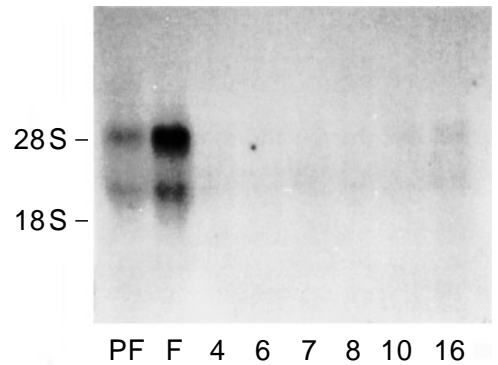

Fig. 4. Time course of expression of the PDGF-receptor during growth and differentiation of 3T 3-L 1 cells to the adipocyte-like phenotype. Total R NA from the indicated cells was hybridized with the PDG F- $\alpha$ receptor-specific probe. PF, preconfluent cells on day 4 after plating; $F$, confluent fibroblasts on day 7. Numbers designate the days after induction of the differentiation. A II lanes contained equal amounts of R NA as judged from ethidium bromide staining and hybridization with other probes e. g., A R L 1, A R L 4 and G L U T 4 [36]

The data on the PDG F-stimulated receptor autophosphorylation (Fig.3) suggested a differential expression of the PDGF receptors in 3T 3-L 1 cells. Thus, a Northern blot analysis of PDGF receptor MR NA in 3T 3-L 1 cells during differentiation was carried out with probes specific for either isotype. In the Northern blot obtained with a probe specific for the PDGF- $\alpha$ receptor (Fig.4), two transcripts were detected in growing, pre-confluent cells (PF, day 4 after plating). Two days after confluence ( $F$, day 7 after plating), the intensity of the signals from both transcripts was approximately doubled. Thereafter, the mRNA levels of PDGF- $\alpha$ receptors decreased to nearly undetectable levels at day 4 after initiation of differentiation. With a specific probe for the PDGF$\beta$ receptor, considerably weaker signals were detected in fibroblasts which decreased to undetectable levels in the adipocytes (data not shown).

In order to compare the differences in the PDGF receptor expression in fibroblasts and adipocytes with those in glucose transport stimulation, the effects of PDGF-A A and PDGF-BB on glucose transport activity were studied with the 2-deoxyglucose uptake method. In confluent 3T3-L 1 fibroblasts, PDGF-AA as well as PDGF-BB produced an approximately six to eight-fold stimulation of 2-deoxyglucose uptake (Fig.5). Half-maximal stimulation was observed at a concentration range between 0.1 and $1 \mathrm{nmol} / \mathrm{l}$. The magnitude of the stimulatory effect of PDGF-A A was similar to that of insulin; that of PDGF-B B was even greater than that of insulin. In differentiated cells (note the different ordinate scale), insulin produced an approximately 25 -fold stimulation of the 2-deoxyglucose uptake (Fig.5, right panel). In contrast, PD GF-A A and PDGF-BB produced a much lower stimulation which amounted to only a small portion of that seen with insulin. A gain, the effect of PDGF-BB was clearly higher than that of PDGF-A A. 


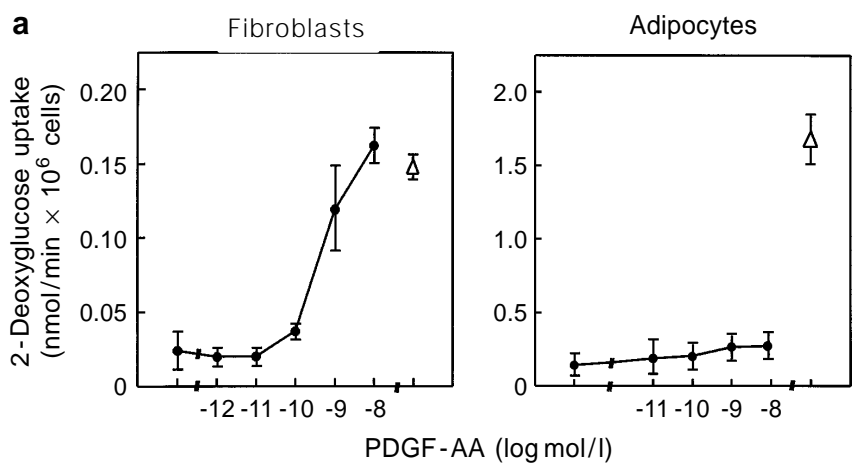

b Fibroblasts
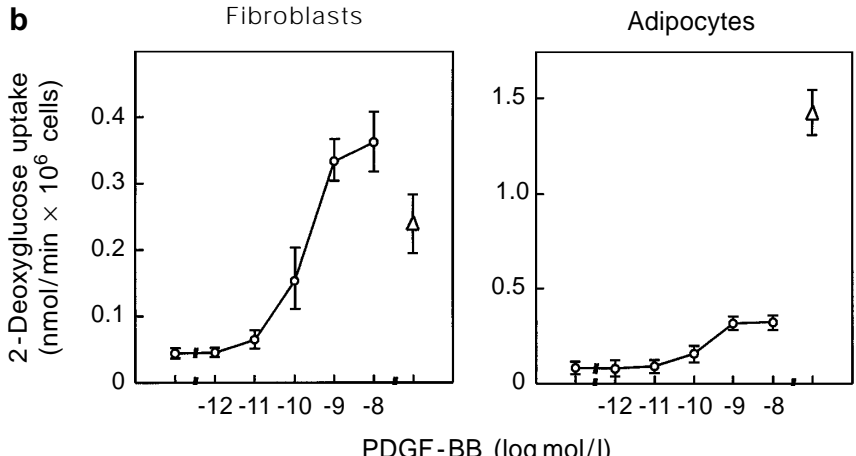

PDGF-BB (log $\mathrm{mol} / \mathrm{l})$

Fig. 5a, b. E ffects of PDG F-A A (a) and PDG F-B B (b) on glucose uptake in 3T 3-L 1 cells. 3T 3-L 1 cells (left panels, fibroblasts; right panels, adipocytes) were incubated for $20 \mathrm{~min}$ with the indicated concentrations of PDGF-AA (O), PDGF$B B(\bigcirc)$ or insulin $(250 \mathrm{nmol} / \mathrm{l}, \triangle)$. G lucose uptake was determined with tritiated 2-deoxyglucose as described in $M$ aterials and methods. $D$ ata represent means \pm SE $M$ of at least three independent experiments, each performed with duplicate samples

E ffects of Wortmannin on glucose transport activity stimulated by insulin, IGF-I, and PDGF. PI 3-kinase is stimulated by insulin and has been suggested to mediate the effect of insulin on glucose transport [28, 29]. Furthermore, the specific PI 3-kinase inhibitor Wortmannin is known to inhibit insulin-stimulated translocation of GLUT 1 and G LUT 4 in 3T 3-L 1 adipocytes [30]. B ased on the assumption that PI 3-kinase plays a crucial role in all signalling pathways leading to an insulin-like transporter translocation, we anticipated that Wortmannin would inhibit all stimulatory effects of the growth factors. Indeed, as is shown in Figure 6, Wortmannin inhibited 2-deoxyglucose uptake stimulated by insulin, IGF-I, and PDGF in a concentration-dependent manner. The I $\mathrm{C}_{50}$ values of Wortmannin were similar (approximately $20 \mathrm{nmol} / \mathrm{l}$ ) for the stimulation of glucose transport by insulin $(250 \mathrm{nmol} /$ I), IGF-I and PDGF. I nterestingly, the I $C_{50}$ value of Wortmannin was lower at low insulin concentrations ( $3 \mathrm{nmol} / \mathrm{l}$; upper right panel of Fig. 6). The latter finding strongly suggests a competitive component of the effects of insulin and Wortmannin, and further strengthens the previous conclusion $[28,29]$ that the effect of insulin on 2-deoxyglucose uptake is mediated by activation of PI 3-kinase.

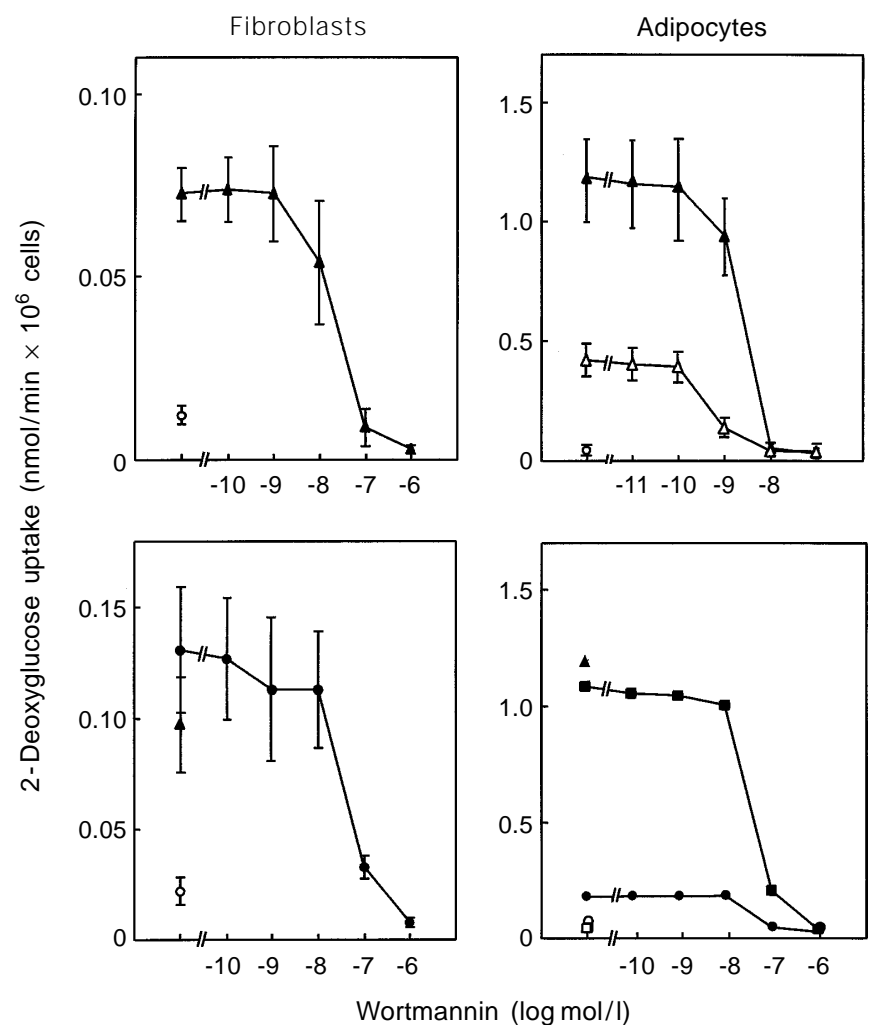

Fig. 6. Inhibition of insulin, IG F-I, and PDG F-stimulated glucose uptake by Wortmannin in 3T 3-L 1 cells. 3T 3-L 1 cells (left panels, fibroblasts; right panels, adipocytes) were incubated for $30 \mathrm{~min}$ with the indicated concentrations of Wortmannin and insulin $(250 \mathrm{nmol} / \mathrm{L} \boldsymbol{\Delta} ; 3 \mathrm{nmol} / \mathrm{l} \Delta$ ), PDGF-BB (fibroblasts, $10^{-9} \mathrm{~mol} / \mathrm{l}$; adipocytes; $\left.10^{-8} \mathrm{~mol} / \mathrm{l}\right)$ and IGF-I $\left(10^{-8}\right.$ $\mathrm{mol} / \mathrm{l}, \square$ ) or without hormone $(\bigcirc \square$ ). Glucose uptake was determined with tritiated 2-deoxyglucose as described in $\mathrm{M}$ aterials and methods. $D$ ata represent means \pm SE M of three experiments or means of duplicate samples from a representative experiment (lower right panel)

\section{Discussion}

Signalling pathways interact through a complex network of regulation which modulates the cellular response to different, simultaneously acting stimuli. R ecently, cross-talk between a JA K /STA T pathway and components of the tyrosine kinase receptor pathways has been demonstrated $[19,18]$. It was shown that IR S-1, the primary substrate and adaptor of the insulin receptor, plays an essential role in the mitogenic effects of IL -4 . F urthermore, $M$ ap-kinase appears to mediate not only effects controlled by tyrosine kinase receptors but also the cellular response to interferons [31, 32]. Thus, based on the hypothesis that JA K kinases can phosphorylate IR S-1, it was conceivable that glucose transport is stimulated by receptors triggering JA K /STA T pathways. In order to test this assumption, we studied the effects of IL -6 and interferon- $\gamma$, which activate different transcription factors (Stat3 and Stat1) through related pathways involving Jak1, Jak2 and Tyk2. In addition, experiments were 
performed with IL -4 which activates Stat6 through Jak 1 and Jak3.

The present data indicate that both IL -6 and interferon- $\gamma$ failed to increase 2-deoxyglucose uptake rates or stimulate IR S-1 phosphorylation in 3T 3-L 1 cells. Conversely, insulin was without detectable effect on A PRF/Stat3 or Statl activation as demonstrated in the gel retardation assays. Thus, our data demonstrate a lack of cross-talk between the IL -6 or interferon- $\gamma$ controlled JAK/STA T pathways, and the insulin/IG F-I receptor pathway in 3T 3-L 1 cells. It has to be noted, however, that this conclusion is restricted to the JA K isoforms which associate with the IL - 6 receptor/gp130 complex or the interferon- $\gamma$ receptor (Jak1, Jak2, Tyk2). The data cannot rule out that other JAK isoforms are capable of triggering the pathway that initiates translocation of glucose transporters. Furthermore, we cannot discount the possibility that the failure of I L -4 to stimulate glucose transport is due to a lack of I L -4 receptors or the Jak3 kinase in 3T 3-L 1 cells.

The present data indicate that both PDGF-A A and PD G F-B B exert the full effect of insulin in undifferentiated fibroblasts (six - eight-fold stimulation), but failed to stimulate more than $20 \%$ of the maximal effect of insulin in adipocytes. Thus, the data confirm previous reports indicating differences in the signalling potential of insulin and PDGF receptors in 3T 3- $L 1$ cells $[33,15-17]$. The data are compatible with the conclusion that PDGF receptors produce a full insulin-like translocation of GLUT1, which is predominant in fibroblasts, but not of G LUT4, which is present only in the adipocytes. This conclusion has previously been proposed based on findings with the impermeant bis-mannose photolabel [15]. Furthermore, since PD G F failed to stimulate IR S-1 phosphorylation in both phenotypes of the 3T3-L 1 cell, it might be speculated that I R S-1 phosphorylation is required for insulin-stimulated translocation of GLUT 4 but not of G LUT 1.

We have shown here that levels of $\mathrm{mR} N \mathrm{~A}$ and protein of PD G F receptors are markedly decreased after differentiation of 3T 3-L 1 cells. Thus, the possibility hasto be considered that the failure of PD G F to stimulate the full insulin response in adipocytes is due to this loss of PDG F receptors. Previous reports suggesting that PD G F produces a full stimulation of PI 3-kinase in adipocytes $[16,17]$ appear to argue against this conclusion. We cannot fully discount the possibility that the differentiation-dependent loss of receptors is specific for the 3T 3-L 1 clone used in our laboratory. H owever, the previous conclusion [16, 17] that PI 3-kinase is necessary, but not sufficient for the insulin-stimulated translocation of GLUT4 is not incompatible with our data. It is conceivable that the reduced number of receptors is sufficient for full PI 3-kinase activation, but insufficient for the presumed additional signalling event(s) required for G L U T 4 translocation.
Previous studies with Chinese hamster ovary ( $\mathrm{CHO}$ ) cells overexpressing both PDGF-receptors and GLUT 4 indicate that the PD G F-receptor is capable of mediating a stimulation of glucose transport [34]. Furthermore, it has recently been shown that epidermal growth factor (E G F)-receptors when overexpressed in 3T 3-L 1 adipocytes [35] can produce the full effect of insulin on glucose transport. Together with our data showing the full effect of PDG F on glucose transport in the 3T 3-L 1 fibroblasts, these data indicate that the receptors for insulin, PDGF and E G F elicit similar, if not identical cellular responses, probably by virtue of similar and in part identical transduction mechanisms. Consequently, as far as these receptors are concerned, the quality and specificity of a cellular response appears to be determined by the hormone binding domain of the receptor rather than its intracellular domain and/or the signalling cascade.

A cknowledgements. This study was supported by grants from the Deutsche Forschungsgemeinschaft (Jo 117/6-2 and SFB 351).

\section{References}

1. Fantl WJ, Johnson DE, Williams LT (1993) Signalling by receptor tyrosine kinases. A nnu $R$ ev B iochem 62: 453-481

2. Kazlauskas A, Cooper JA (1989) A utophosporylation of the PD G F receptor in the kinase insert region regulates interactions with cell proteins. Cell 58: 1121-1133

3. Skolnik EY, M argolis B, M ohammadi M et al. (1991) Cloning of PI3 kinase-associated p85 utilizing a novel method for expression/cloning of target proteins for receptor tyrosine kinases. Cell 65: 83-90

4. Koch CA, A nderson D, M oran MF, Ellis Ch, Pawson T (1991) SH 2 and SH 3 domains: elements that control interactions of cytoplasmic signaling proteins. Science 252: 668-674

5. K azlauskas A, Kashishian A, Cooper JA, Valius M (1992) GTPase-activating protein and phosphatidylinositol 3-kinase bind to distinct regions of the platelet-derived growth factor receptor beta subunit. M ol Cell Biol 12: 2534-2544

6. Twamley-Stein GM, Pepperkok R, A nsorge W, Courtneidge SA (1993) The Src family tyrosine kinases are required for platelet-derived growth factor-mediated signal transduction in NIH 3T 3 cells. Proc Natl A cad Sci USA 90: 7696-7700

7. E gan SE, Giddings BW, B rooks M W, Buday L, Sizeland A M, Weinberg RA (1993) A ssociation of Sos R as exchange protein with $\mathrm{Grb} 2$ is implicated in tyrosine kinase signal transduction and transformation. N ature 363: 45-51

8. Backer J M, M yers jr M G, Shoelson SE et al. (1992) Phosphatidylinositol 3'-kinase is activated by association with IR S-1 during insulin stimulation. E M B O J 11: 3469-3479

9. Sun X J, Wang L M, Zhang Y et al. (1995) R ole of IR S-2 in insulin and cytokine signalling. N ature 377: 173-177

10. Weiland M, B ahr F, H öhne M, Schürmann A, Z iehm D, Joost HG (1991) The signaling potential of the receptors for insulin and insulin-like growth factor I (IG F-I) in 3T 3$L 1$ adipocytes: comparison of glucose transport activity, induction of oncogene c-fos, glucose transporter mR NA, and D N A -synthesis. J Cell Physiol 149: 428-435 
11. Rubin CS, H irsch A, Fung C, R osen OM (1978) D evelopment of hormone receptors and hormonal responsiveness in vitro. Insulin receptors and insulin sensitivity in the preadipocyte and adipocyte forms of 3T 3-L 1 cells. J Biol Chem 253: 7570-7578

12. Weiland M, Schürmann A, Schmidt WE, J oost H G (1990) D evelopment of the hormone-sensitive glucose transport activity in differentiating 3T 3-L 1 murine fibroblasts. R ole of the two glucose transporter species and their subcellular localization. B iochem J 270: 331-336

13. Yang J, Clark AE, Kozka IJ, Cushman SW, H olman GD (1992) Development of an intracellular pool of glucose transporters in 3T 3-L 1 cells. J B iol Chem 267: 10393-10399

14. Ziehm D, Schürmann A, Weiland M, Joost H G (1993) Biphasic alteration of glucose transport in 3T 3- $\mathrm{L} 1$ cells during differentiation to the adipocyte-like phenotype. Horm M etab R es 25: 71-76

15. G ould G W, M errall NW, M artin S et al. (1994) G rowth factor-induced stimulation of hexose transport in 3T 3-L 1 adipocytes: evidence that insulin-induced translocation of GLUT4 is independent of activation of map kinase. Cell Signal 6: 313-320

16. Isakoff SI, Taha C, R ose E, M arcusohn J, K lip A, Skolnik EY (1995) The inability of PI3 kinase activation to stimulate GLUT4 translocation indicates additional signaling pathways are required for insulin-stimulated glucose uptake. Proc N atl A cad Sci U SA 92: 10247-10251

17. Wiese R J, M astick CC, L azar D F, Saltiel A R (1995) A ctivation of mitogen-activated protein kinase and phosphatidylinisitol 3 '-kinase is not sufficient for the hormonal stimulation of glucose uptake, lipogenesis, or glycogen synthesis in 3T 3-L 1 adipocytes. J B iol Chem 270: 3442-3446

18. Keegan A D, Nelms K, White $M$, Wang LM, Pierce JH, Paul WE (1994) A n IL -4 receptor region containing an insulin receptor motif is important for IL-4-mediated IR S-1 phosphorylation and cell growth. Cell 76: 811-820

19. Wang $L M, M$ yers jr $M G$, Sun $X J$, A aronson SA, White $M$, Pierce JH (1993) IRS-1: essential for insulin- and IL -4stimulated mitogenesis in hematopoietic cells. Science 261: 1591-1594

20. Taga T, H ibi M , H irata $Y$ et al. (1989) Interleukin- 6 triggers the association of its receptor with a possible signal transducer, gp130 Cell 58: 573-581

21. Mackiewiecz A, Schooltink H, Heinrich PC, R ose-J ohn S (1992) Complex of soluble human IL -6-receptor/I L-6 upregulates expression of acute-phase proteins. J Immunol 149: 2021-2027

22. Lütticken C, Wegenka U M, Y uan J et al. (1994) A ssociation of transcription factor A PR F and protein kinase Jak1 with the interleukin-6 signal transducer gp130. Science 263: 89-92

23. Ihle J N (1995) Cytokine receptor signalling. Nature 377: 591-594

24. Weiergräber O, H emmann V, Kuster A et al. (1995) Soluble human interleukin-6 receptor. E ur J B iochem 234: 661-669
25. A ndrews NC, Faller DV (1991) A rapid micropreparation technique for extraction of DNA -binding proteins from limiting numbers of mammalian cells. $\mathrm{Nucl}$ A cids Res 19: 2499

26. Wegenka UM, Buschmann J, L ütticken C, Heinrich $P C$, Horn F (1993) A cute-phase response factor, a nuclear factor binding to acute-phase response elements, is rapidly activated by interleukin- 6 at the posttranslational level. M ol Cell Biology 13: 276-288

27. Wegenka U M, L ütticken C, B uschmann J et al. (1994) The interleukin-6-activated acute-phase response factor is antigenically and functionally related to members of the signal transducer and activator of transcription (STAT) family. Mol Cell Biol 14: 3186-3196

28. O kada T, K awano Y, Sakakibara T, H azeki O, U i M (1994) Essential role of phosphatidylinositol 3-kinase in insulininduced glucose transport and antilipolysis in rat adipocytes. J B iol Chem 269: 3568-3573

29. H ara K, Y onezawa K, Sakaue H et al. (1994) 1-phosphatidylinositol 3-kinase activity is required for insulin-stimulated glucose transport but not for RAS activation in CHO cells. Proc Natl A cad Sci 91: 7415-7419

30. Clarke JF, Y oung PW, Y onezawa K, K asuga M, H olman GD (1994) Inhibition of the translocation of GLUT 1 and GLU T4 in 3T 3-L 1 cells by the phosphatidylinositol 3-kinase inhibitor, wortmannin. B iochem J 300: 631-635

31. $Y$ in T, Y ang Y C (1994) M itogen-activated protein kinases and ribosomal $\mathrm{S} 6$ protein kinases are involved in signaling pathways shared by interleukin-11, interleukin-6, leukemia inhibitory factor, and onocostatin $\mathrm{M}$ in mouse 3T 3-L 1 cells. J Biol Chem 269: 3731-3738

32. D avid M, Petricoin III E, B enjamin C, Pine R, Weber MJ, Larner A C (1995) R equirement for map-kinase (ER K 2) activity in interferon alpha- and interferon beta-stimulated gene expression through STAT proteins. Science 269: $1721-1723$

33. M errall NW, Wakelam M J O, Plevin R, Gould G W (1993) Insulin and platelet-derived growth factor acutely stimulate glucose transport in 3T 3-L 1 fibroblasts independently of protein kinase C. Biochim Biophys A cta 1177: 191-198

34. K amohara S, H ayashi H, Todaka M et al. (1995) Plateletderived growth factor triggers translocation of the insulinregulatable glucose transporter (type 4) predominantly through phosphatidylinositol 3-kinase binding sites on the receptor. Proc N atl A cad Sci 92: 1077-1081

35. $\mathrm{H}$ ardy $\mathrm{R}$ W, G upta K B, M CD onald J M, Williford J, Wells A (1995) E pidermal growth factor (E GF) receptor carboxyterminal domains are required for EFG-induced glucose transport in transgenic 3T 3-L 1 adipocytes. E ndocrinology 136: 431-439

36. Schürmann A, B reiner M, Becker W et al. (1994) Cloning of two novel ADP-ribosylation factor-like proteins and characterization of their differential expression in 3T 3-L 1 cells. J Biol Chem 269: 15683-15688 